\title{
Presupuesto nacional y gastos sociales
}

La intermediación del Estado en la distribución de los beneficios del crecimiento es una cóndición básica para impulsar el desarrollo económico y social, muy especialmente en el marco de un modelo de desarrollo basado en la promoción de las exportaciones, el cual supone la adopción de medidas que podrían afectar negativamente el ingreso real de las familias y elevar la pobreza en el país donde esto se ponga en práctica. Una elevación del tipo de cambio nominal o un incremento de los impuestos a las transacciones internas, por ejemplo, ocasiona incrementos proporcionales en los precios y una disminución del ingreso real de la población.

Hasta ahora no se ha procedido a devaluar el tipo de cambio nominal, pero sí podría señalarse algún deterioro en las condiciones de vida de la población, reflejado en una regresión en la distribución del ingreso y en un crecimiento desproporcional entre los precios y los ingresos en favor de los primeros. Pese a lo anterior, el gobierno aún no se decide a iniciar la creación de las condiciones necesarias para mitigar los efectos del programa de ajuste. Uno de los principales postulados económicos del gobierno actual es limitar la acción del Estado a funciones esenciales, que no intervengan directamente en la actividad económica. La prestación de servicios sociales básicos para la población más desfavorecida es una de las funciones esenciales del Estado, lo cual fue reconocido por el presidente Cristiani al inicio de su gestión, cuando anunció la adopción de medidas para combatir la pobreza extrema.

Sin embargo, durante su gestión, el gobierno actual no ha cambiado significativamente el papel del Estado en la atención de los sectores pobres. Los recursos que se canalizan a las diferentes instituciones del área social son claramente insuficientes para atender la creciente demanda de servicios sociales básicos. Esta deficiencia es injustificable en un país con las características de El Salvador, donde la tasa de analfabetismo está cerca del 30 por ciento a nivel nacional, la cobertura escolar urbana es de sólo 35 por ciento, el promedio escolar urbano es de 4.5 grados, el 30 por ciento de la población infantil sufre de daños nutricionales, el 50 por ciento de las familias se encuentra con déficit energético, existe una mortalidad infantil cercana a los 56 por cada mil nacidos vivos, una esperanza de vida de 63 affos, etc.

El Presupuesto General de la Nación y la forma en que está siendo financiado son una fiel muestra de la desatención que el gobierno está dando al área social y del sentido que el gobierno de ARENA otorga a la función financiera del Estado.

Al examinar la evolución de las asignaciones presupuestarias durante las últimas dos décadas, una de las tendencias más notorias que puede detectarse es el desplazamiento de los gastos sociales por los gastos militares y los destinados al servicio 
de la deuda pública. Algunas cifras pueden lograr aclarar las dimensiones del desplazamiento para 1994.

Fuera de los rubros de defensa y servicio de la deuda, no se detectan otros áreas del presupuesto que expliquen la disminución de los recursos para el área social. Al agrupar el resto de dependencias públicas y de los poderes del Estado en el rubro de "otros", resulta que su participación porcentual en el presupuesto ha estado descendiendo en los últimos 34 anos.

Por otro lado, ateniéndonos a las proyecciones del gobierno para 1994, el presupuesto de la nación dedicado al servicio de la deuda pública podría alcanzar un total equivalente al 3.5 por ciento del PIB y a un 22.03 por ciento del total del presupuesto, situación que contrasta fuertemente con los mismos porcentajes correspondientes al año de 1974, cuando el servicio de la deuda apenas alcanzaba un 1.1 por ciento del PIB y sólo un 6.2 por ciento del total del presupuesto para ese año.

Adicionalmente, los gastos en defensa y seguridad pública también han experimentado incrementos de consideración durante los últimos veinte años. De acuerdo a los datos del Cuadro 1, en 1974 el presupuesto para defensa y seguridad pública representó el 1.4 por ciento del PIB y el 7.42 por ciento del presupuesto de ese año. En 1994, este presupuesto puede llegar a representar el 2.4 por ciento del PIB y el 15.02 por ciento del total del presupuesto. El incremento de los gastos militares fue más notorio durante el desarrollo del conflicto armado, en el año 1981, por ejemplo, éste llegó a representar el 3.4 por ciento del PIB y el 15.2 por ciento del total del presupuesto.

En contrapartida, los gastos sociales han experimentado una fuerte disminución. De aprobarse al presupuesto de 1994, los gastos sociales pasarian de representar el 6.1 por ciento del PIB y el 32.71 del presupuesto nacional en 1974 a representar sólo el 3.8 por ciento y el 23.87 por ciento, respectivamente, para el año 1994.

En términos de gasto por habitante, puede notarse que entre 1990 y 1994 ha habido alguna recuperación del gasto social (de 16.53 a 22.80 colo- nes constantes de 1962), pero aún no se ha logrado llevar este gasto por habitante a niveles similares a los de 1974 ó 1981 (35.43 y 42.44 colones constantes de 1962, respectivamente), pese a que se ha experimentado un apreciable incremento de la producción durante los últimos tres años. Esta situación obedece, en buena medida, a la indisposición del gobiemo para dedicar proporciones mayores del presupuesto a los gastos sociales, en virtud de dar cumplimiento a otras obligaciones y exigencias. La evolución reciente del presupuesto también podría ayudar a aclarar la verdadera política social que el gobiemo de ARENA está ejecutando.

En el caso del Ministerio de Educación, aunque los funcionarios señalan un incremento de más de 300 millones de colones en relación al presupuesto de 1993, se omite decir que en términos de porcentajes, el Ramo de Educación apenas aumentó su participación en un 0.18 por ciento del total del presupuesto (del 14.49 al 14.67 por ciento). Por otra parte, el Ramo de Salud Pública y Asistencia Social pasó de representar el 9.56 por ciento del presupuesto de 1993 a representar el 9.20 por ciento del total en 1994 , es decir, disminuyó en 0.36 por ciento.

Un balance de los presupuestos diseñados e implementados por la actual gestión de ARENA mostraria que entre 1990 y 1994 , el gasto social pasó de representar el 25.53 por ciento del presupuesto a representar el 23.87 por ciento; por otra parte, en los mismos años, la deuda pública pasó de absorber un 13.5 por ciento del presupuesto à absorber 22.03 por ciento. En 1992, el servicio de la deuda pública alcanzó el récord del 28.96 por ciento del presupuesto general de la nación, es decir, más de la cuarta parte. En 1993, la cifra disminuyó hasta el 20.84 por ciento, volviendo a aumentar en 1994, tal como ya se mencionó arriba. El incremento del servicio de la deuda alcanzará cerca de los 580 millones de colones. Las obligaciones generales del gobierno también aumentarán su participación entre 1993 y 1994, al pasar del 7.26 al 7.6 por ciento.

Por otra parte, el gasto de defensa y seguridad pública, aunque ha disminuido en relación a 1990, aún se encuentra en índices históricos altos si se 
Indicadores de la evolución del gasto público

Algunos gastos estatales como porcentaje del PIB

\begin{tabular}{lccccc}
\hline & 1960 & 1974 & 1981 & 1990 & 1994 \\
\hline Gasto social & 4.2 & 6.1 & 6.2 & 2.6 & 3.8 \\
Defensa y seguridad pública & n.d & 1.4 & 3.4 & 2.7 & 2.4 \\
Deuda pública & n.d. & 1.1 & 1.8 & 1.4 & 3.5 \\
Total & n.d. & 18.9 & 22.2 & 10.36 & 15.9 \\
\hline
\end{tabular}

Gastos por habitante

(Colones de 1962)

\begin{tabular}{lrrrrr}
\hline Gasto social & 19.50 & 35.43 & 42.44 & 16.53 & 22.80 \\
Defensa y seguridad pública & 8.34 & 8.04 & 23.13 & 17.03 & 14.34 \\
Deuda pública & 2.73 & 6.73 & 12.57 & 8.74 & 21.04 \\
Total & 66.47 & 108.31 & 152.26 & 64.84 & 95.52 \\
\hline
\end{tabular}

Estructura porcentual del presupuesto de la nación

\begin{tabular}{|c|c|c|c|c|c|}
\hline Gasto social & 29.4 & 32.71 & 27.86 & 25.53 & 23.87 \\
\hline Defensa y seguridad pública & 12.54 & 7.42 & 15.20 & 26.27 & 15.02 \\
\hline Deuda pública & 4.1 & 6.2 & 8.30 & 13.50 & 22.03 \\
\hline Otros & 53.94 & 53.67 & 48.64 & 34.70 & 39.08 \\
\hline Total & 100.0 & 100.0 & 100.0 & 100.0 & 100.0 \\
\hline
\end{tabular}

* En base a proyecciones de población, PIB e índice de precios al por mayor.

Fuente: en base a datos de la Revista Mensual del Banco Central de Reserva y la Ley General del Presupuesto, varios años.

considera que en 1962 y 1974 representaron el 12.54 y el 7.42 por ciento del presupuesto total. Los ramos de defensa y seguridad pública han drenado una fuerte cantidad de recursos públicos desde antes desde que se iniciara la década pasada. De acuerdo a datos oficiales, durante la década de los ochenta, el gasto asignado a los rubros de defensa y seguridad pública pasó de absorber el 14.4 por ciento del presupuesto de 1980 a absorber el 26.7 por ciento del correspondiente a 1989. En 1994, el gasto en estos rubros descenderá hasta un 10.98 por ciento sin tomar en cuenta los presupuestos de la Policía Nacional Civil y la Academia Nacional de Seguridad Pública que representan juntos el 3.99 por ciento.

Esta cifra aún resulta demasiado elevada, con- siderando la finalización de la guerra civil y la severa reducción de efectivos que habría experimentado la Fuerza Armada, lo cual inevitablemente conduce a una reducción apreciable de gastos operacionales y de pago de salarios.

La carga de la deuda externa y de los gastos de defensa reduce el margen de maniobra de cualquier gobierno para mejorar la participación del Estado en la prestación de servicios sociales, e inclusive para promover el desarrollo económico. Una vez finalizado el conflicto, el problema mayor parece centrarse en la pesada carga que la deuda externa ha pasado a representar.

Además del presupuesto general de la nación, existe un presupuesto extraordinario $y$, actualmen- 
te se ha creado una partida presupuestaria para el Fondo de Inversión Social. La introducción de estos presupuestos tiende a complicar el examen del presupuesto de la nación, por ello, haremos algunas consideraciones generales sobre ellos.

En el caso del presupuesto extraordinario, la Ministro de Planificación dio a conocer que éste podria alcanzar un monto de 1,971 millones de colones para 1994, provenientes de préstamos y donaciones realizadas por países extranjeros. Según: la ministro, este presupuesto está destinado a financiar los programas de reconstrucción nacional actualmente en ejecución, es decir, básicamente obras de reposición de infraestructura. Así las cosas, esta suma representaría cerca del 21 por ciento del presupuesto general de la nación para 1994. Debe señalarse que el presupuesto extraordinario constituye quizás el mayor aporte para la inversión pública, puesto que del presupuesto ordinario solamente un 22 por ciento se dedica a este fin.

Por su parte, el presupuesto del Fondo de Inversión Social, en teoría, está dedicado a la ejecución de programas de compensación social, en el marco de del programa de ajuste estructural desarrollado por el gobierno. Hasta ahora, el Fondo no ha contado con un presupuesto adecuado para atender la pérdida de ingreso experimentada por los sectores más pobres desde el inicio de la gestión del gobierno actual. El Fondo opera principalmente a partir de préstamos otorgados por el Banco Interamericano de Desarrollo; lo cual exime casi totalmente al gobierno de cualquier responsabilidad en sus acciones.

El Fondo de Inversión Social ha enfrentado durante su funcionamiento límites financieros que no permiten augurar un futuro prometedor para la población pobre. Para enero de 1994, el Fondo habrá invertido un total de 265 millones de colones en obras de desarrollo social (la mitad del incremento del servicio de la deuda pública entre 1993 y 1994), lo cual es una cantidad muy modesta para hacer frente al deterioro de las condiciones de vida de la población urbana que en 1990 se calculó en 1,500 millones de colones. Ni siquiera considerando el reciente préstamo de 60 millones de dólares (520 millones de colones) que el BID le otorgó

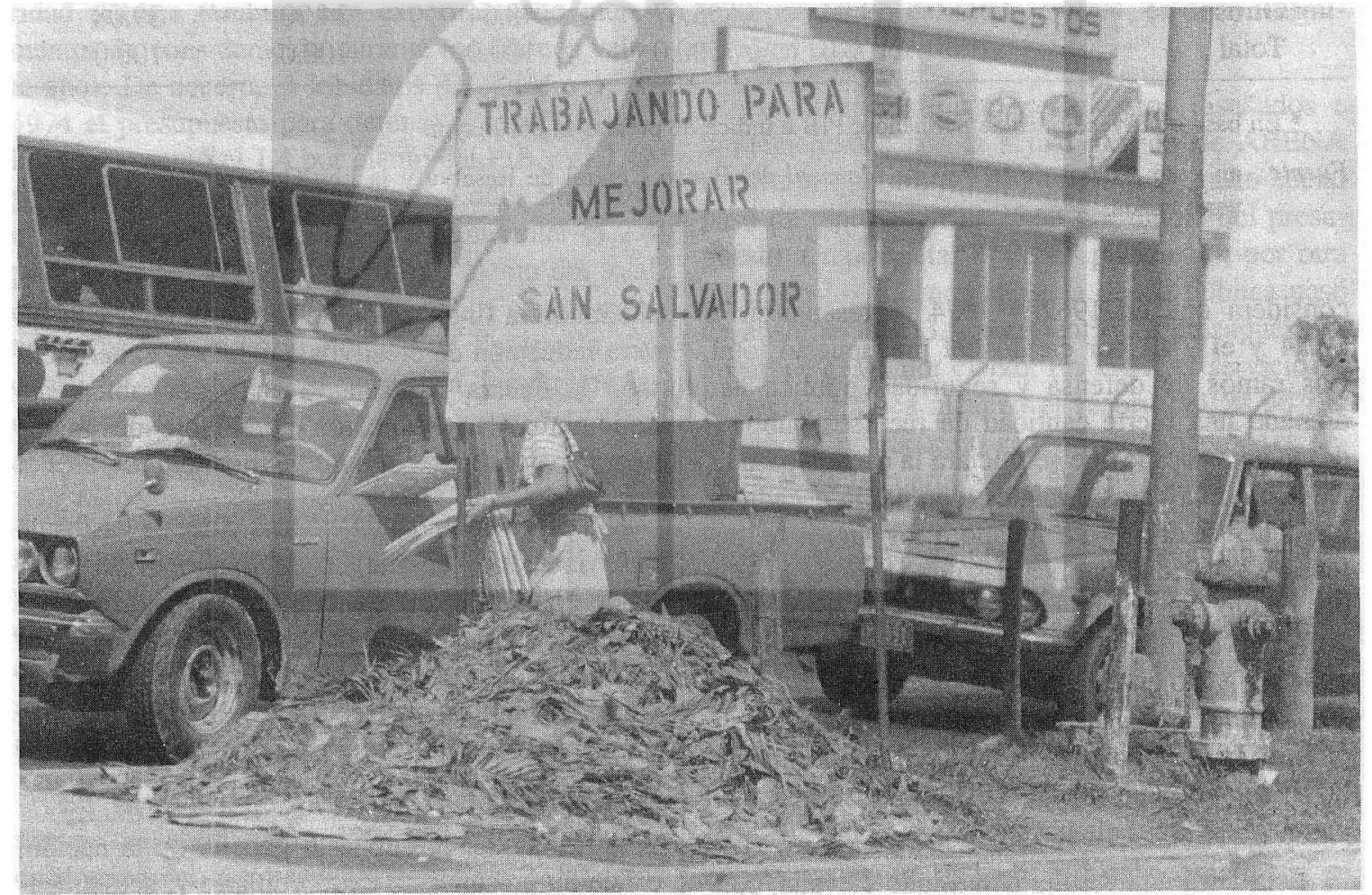


recientemente, el Fondo podrá cubrir la deuda social de 1990, mucho menos la de ahora.

Así pues, estos presupuestos difícilmente podrian tener una incidencia significativa en el balance global del financiamiento estatal para el funcionamiento social, pues las dimensiones de la pobreza en el país exigen presupuestos mucho más elevados y focalizados directamente en los sectores pobres. Condiciones que no son cumplidas ni por el Fondo de Inversión Social, ni por el presupuesto extraordinario.

El financiamiento público también configura un escenario desfavorable para la población de menores ingresos. Al revisar los aspectos de la reforma tributaria que ha perseguido la administración actual y sus efectos sobre la estructura de los ingresos puede detectarse una mayor participación de los impuestos indirectos, lo cual implica que se está promoviendo una estructura tributaria regresiva.

En 1987, las revistas del Banco Central de Reserva muestran que la participación de los impuestos directos en el total de los ingresos tributarios era de sólo un 30 por ciento, mientras que la participación de los impuestos indirectos era considerable, alcanzando el 70 por ciento del total. La situación se mantuvo inalterada hasta 1992, cuando la introducción del Impuesto al Valor Agregado (IVA) aumentó considerablemente la participación de los impuestos indirectos en 1993. Esta situación estaria apuntando hacia la creación de una estructura tributaria aún más regresiva que la ya existente. Según las proyecciones del Ministerio de Hacienda, con el IVA se proyecta recolectar un total cercano a los 2,400 millones de colones anuales. Ello implicaría que los impuestos indirectos aumentarán su participación en el total de los ingresos tributarios en cerca del 15 por ciento.

El Estado además de no ejecutar un gasto social considerable, está financiando el gasto público a través de una estructura tributaria que grava indistintamente a los contribuyentes sin considerar su capacidad de pago. Esta situación reduce los efectos positivos de cualquier política social destinada a reducir la pobreza porque reduce el ingreso disponible de estos mismos sectores.
Dando por descontada la imposibilidad de una redistribución del ingreso a corto plazo, el combate de la pobreza pasa necesariamente por un aumento del gasto social del gobierno, el cual debería financiarse con un incremento de los ingresos fiscales. Sin embargo, este gasto social no debería ser financiado con recursos provenientes de los mismos sectores a los que se dirige, pues ambas medidas obrarian en sentido opuesto, disminuyendo así el efecto final sobre el ingreso y las condiciones de vida. Es precisamente esto último lo que la reforma tributaria del gobiemo ha venido propiciando. En este contexto, es muy cuestionable que se estén obteniendo recursos financieros de los sectores de menores ingresos, los cuales lejos de destinarse para financiar un mayor gasto social, son destinados para el servicio de la deuda pública y para defensa y seguridad.

La capacidad de atención social del Estado no es capaz de hacer frente al crecimiento natural de la población, evitando el deterioro del gasto público real por habitante en educación y salud. De acuerdo a las fuentes oficiales, el incremento del presupuesto de 1994 (casi 2,000 millones de colones, los cuales representan un 30 por ciento de incremento en relación a 1993) habría sido posible por el éxito de la política tributaria y por el crecimiento de la economía, que se estima llegará al 5 por ciento en 1994. De las valoraciones anteriores y de la evolución del presupuesto se infiere entonces que los mayores beneficios del crecimiento económico y del incremento de los impuestos se lo estarían apropiando los acreedores del país y, además, estarían siendo dedicados a mantener un exagerado aparato militar.

Adicionalmente, el éxito de la política tributaria ha sido a costa de una expansión de los impuestos indirectos, entre ellos el IVA, los cuales gravan indistintamente a los contribuyentes, sin que por ello los más pobres reciban mayores servicios sociales por parte del Estado.

La política neoliberal asumida por ARENA a instancia de los mayores acreedores del país ha mostrado estar creando condiciones para garantizar el cumplimiento de las obligaciones contraídas -y por contraer- por el gobierno y, además, el 
beneficio de los sectores que perciben los mayores ingresos. Los efectos positivos del supuesto crecimiento con estabilidad que el país estaria experimentando, aún no se evidencian en la distribución del ingreso, según se desprende de datos recientes del Ministerio de Planificación.

Pese a que en el discurso oficial se maneja la idea de luchar contra la extensión de la pobreza, en la práctica, poco se hace por ello, al relegar la adopción de una política social que enfrente los problemas distributivos que generan las medidas de política económica.

En las décadas pasadas se evidenció que el crecimiento económico por sí mismo no garantiza el bienestar social. El Estado tiene un importante papel que desempenar para lograr una mejor distribución de los beneficios del crecimiento. Actualmente, los índices del presupuesto general de la nación se encuentran muy lejos de los niveles de las décadas pasadas, cuando la situación tampoco era buena, sin que se vislumbren posibilidades para que éste se racionalice en función del desarrollo social, a menos que se piense en efectuar una reforma tributaria progresiva o que se organice el presupuesto teniendo como prioridad los gastos sociales.

L. E. R. M.

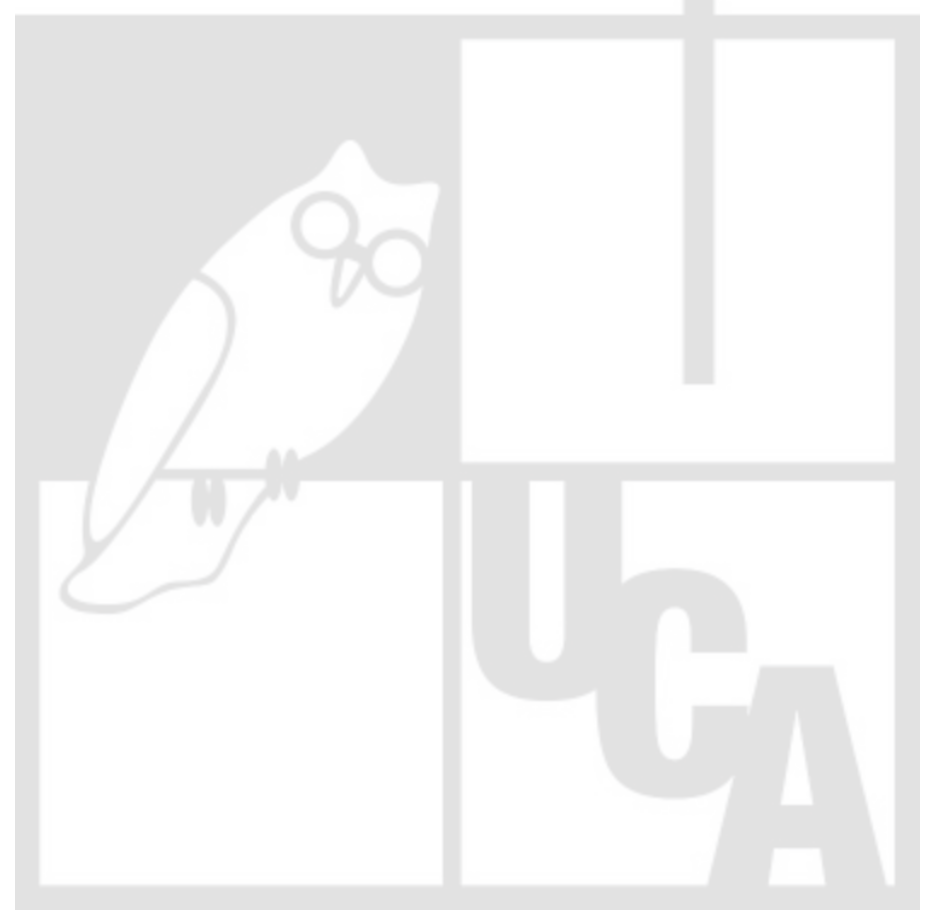

